\title{
Mental health in the smartphone era
}

$\mathrm{E}$ very morning began the same. He would check website after website, monitor breaking news, immerse himself fully in what he called the stream of Internet consciousness. There was also Twitter, and the latest videos, and hot new memes. Scan, cull, curate, comment, repeat. All day. Seven days a week. His popular blog required updating on the half-hour, after all, so the quest for new material never ceased. Until it made him sick.

"By the last few months, I realized I had been engaging - like most addicts — in a form of denial. I'd treated my online life as a supplement to my real life, an add-on, as it were," blogging pioneer Andrew Sullivan wrote in his recent essay for New York Magazine. "But then I began to realize, as my health and happiness deteriorated, that this was not a both-and kind of situation. It was either-or."

Sullivan exhibited what an addiction researcher might call problematic Internet use. Some call it Internet addiction, though that concept remains muchdebated. But few would refute that the rapid rise in popularity of smartphones — now nearly ubiquitous, particularly among young people - has taken this issue to a whole new level.

"Not long ago, surfing the web, however addictive, was a stationary activity. At your desk at work, or at home on your laptop, you disappeared down a rabbit hole of links and resurfaced minutes (or hours) later to reencounter the world," wrote Sullivan. "But the smartphone then went and made the rabbit hole portable, inviting us to get lost in it anywhere, at any time, whatever else we might be doing."

The smartphone also poses a challenge for people who study Internet addiction. The only validated scale in the English language for assessing Internet addition is the Internet Addiction Test (IAT), which was developed in 1998, long before smartphones became commonplace. It contains terms such as Internet "log-ins" and being "off-line."

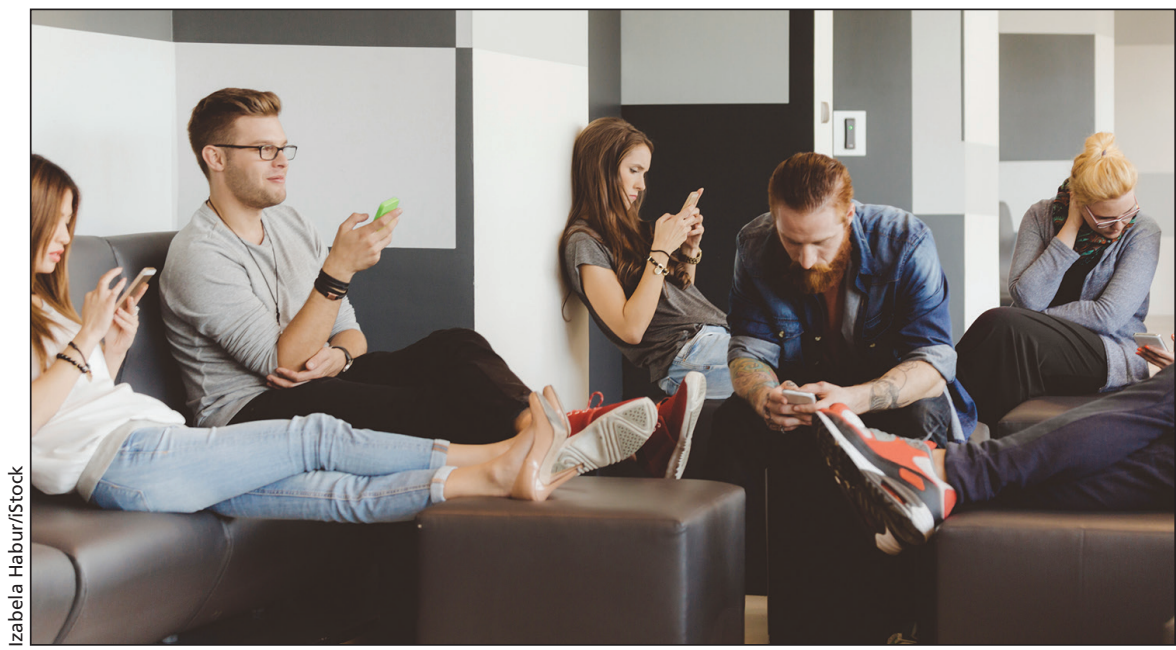

University students who met criteria for problematic Internet use in a survey were also more likely to have symptoms of depression and anxiety.

"In 2016, that is a completely outdated concept," said Dr. Michael Van Ameringen, a professor of psychiatry and behavioural neurosciences at McMaster University in Hamilton, Ontario. "We are always connected now."

Van Ameringen and his team developed a more modern screening tool to identify people with problematic Internet use. He recently presented findings from a survey (not yet published) on the Internet habits of 254 first-year university students at the European College of Neuropsychopharmacology's annual meeting in Vienna, Austria. Though only 33 students met the IAT criteria for Internet addiction, 107 met the new criteria for problematic Internet use.

"People with problematic use had significantly more anxiety and depression symptoms. They had significantly more problems with attention and focusing," said Van Ameringen. "Even more interesting, these people had more functional impairment. It was interfering with school, work and family life."

The areas of Internet use that students reporting having the most trouble controlling were video streaming (55.8\%), social networking $(47.9 \%)$ and instantmessaging $(28.5 \%)$. Some students spent more than six hours a day of their leisure time engaged in these activities.
"Netflix, I think, is the curse of university students ever achieving anything," said Van Ameringen.

The difficulty of distinguishing problematic Internet use from productive Internet use may only grow as more of our day-to-day activities are conducted online and on smartphones. The Internet is where we pay our bills, find directions and read news. It's where we conduct research, manage our investments and keep in touch with relatives. It is vital to many people's jobs. It also so happens to be where we go to seek entertainment.

"People have shifted a lot of their way of life onto the Internet, so that adds to the confusion," said Van Ameringen. "And there is a group who can't control it. They start and they can't stop, and that is the group we are most interested in. When it stops you from doing what you are supposed to do, either at work or school or home, then you have to be concerned about that."

Though Internet addiction has also been shown in other research to be associated with mental health issues, such as depression and anxiety, it is still too early to say if excessive online activity actually causes those problems. It could be that people with mental health issues use the Internet as a coping mechanism. The anonymity of many online commu- 
nities, for example, may be appealing to someone with social anxiety issues.

"The research area of Internet addiction is relatively new and research is just beginning to understand the problem better," Daria Kuss, a senior lecturer in psychology at Nottingham Trent University in the United Kingdom, said in an email.

Relevant research and psychotherapists working in this area do indicate, however, that "comorbidity" of Internet addiction and other mental disorders tends to be common, noted Kuss, the lead author of a recent systematic review on Internet addiction and problematic Internet use in the World Journal of Psychiatry. But the issue of whether the Internet itself is the primary problem, or just a proxy for other issues, remains up for debate.
"This question is a tricky one," said Kuss, "and preliminary evidence would suggest that Internet addiction can be viewed both as a primary disorder (i.e., it is the individual's main concern) as well as a secondary disorder (it appears secondary to say depression or anxiety)." Roger Collier, CMAJ

CMAJ 2016. DOI:10.1503/cmaj.109-5336

\section{Doctors seek legal advice over assisted dying}

$\mathrm{T}$ he Canadian Medical Protective Association (CMPA) opened some 152 legal files for physicians related to medical assistance in dying (MAID) between June 17 (when the federal law took effect) and Aug. 4, 2016.

Since August 2015, the 95 000-member not-for-profit medical mutual defence organization, has opened a total of about 272 files on the issue, Public Affairs Supervisor Joel Baglole stated in an email.

"The spike in call volumes we did receive following June 17 was expected. The rate of new calls seems to be declining somewhat in recent weeks," Baglole said.

The CMPA reaffirmed its commitment to help physicians struggling with new assisted-dying legislation at its recent annual meeting.

Quebec's law on assisted dying was upheld by the courts in 2015, and a federal law received Royal assent in June after passionate debate about whether it conformed to a Supreme Court decision affirming Canadians' right to assisted death.

The CMPA passed resolutions at its 2015 annual meeting calling on the association to help doctors "in matters involving the exercise of their freedoms of conscience, religion, and professional judgement," and expressing concern about "mandatory obligations that interfere with those freedoms."

Outgoing president Dr. Edward Crosby told this year's meeting in Vancouver that "MAID has been a seminal development in our country's laws and in the role our members will be asked to play in a patient's end-of-

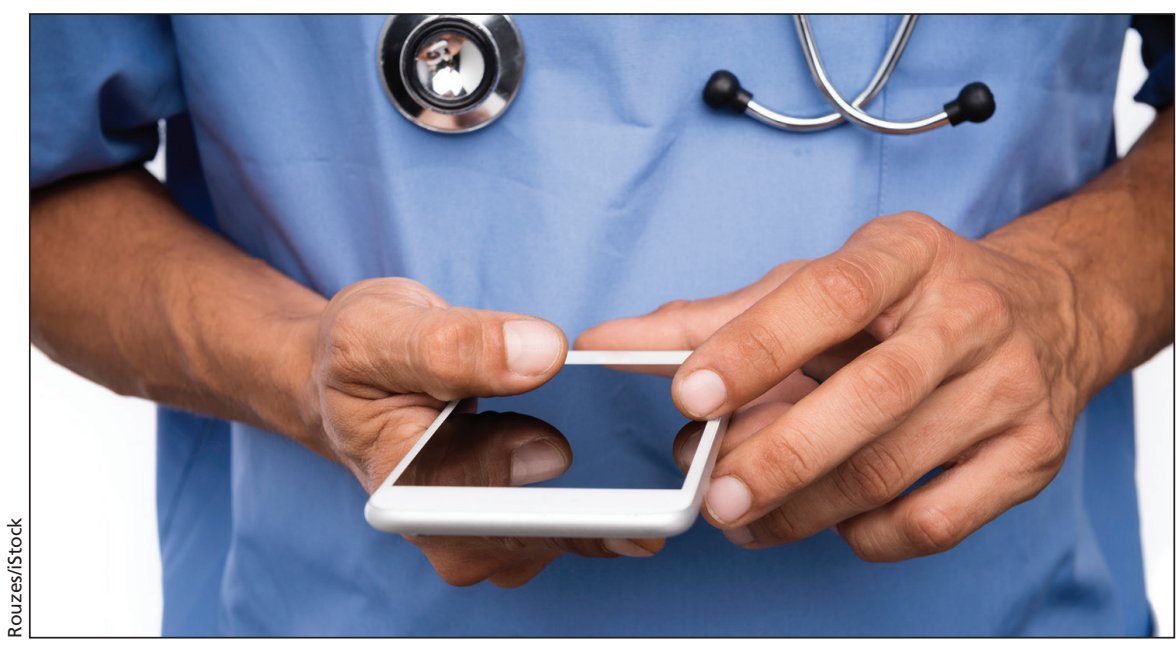

More than $\mathbf{2 0 0}$ doctors have sought legal advice about medically assisted dying.

life care. We have taken what was asked of us seriously."

The association was an active participant as the federal law was drafted and practice standards developed, "always with the objective to provide clarity and consistency across the country, ensure protection for physicians acting in good faith and to protect the interests of our members," said Crosby.

The CMPA was pleased some of its recommendations found their way into new law, he said. They include a statement in the preamble calling for a consistent approach to assisted dying across Canada, clearly spelled out eligibility criteria and safeguards, clear requirements related to the age of consent and need for a "good faith" provision protecting medical practitioners from criminal liability if they acted on an assisted-dying request in an honest but mistaken belief.

"We have seen a reduction in the number of calls from Québec, which can be explained by the fact that institutions in that province have now put in place MAID teams and committees to assist physicians in dealing with a patient's request for MAID," Baglole told CMAJ.

The CMPA and its provincial legal counsel are helping members to ensure they're familiar with and comply with the law's framework, said Baglole. They are also helping doctors understand the eligibility criteria, "especially the requirement that the patient suffers from a grievous and irremediable medical condition."

As well, CMPA lawyers are helping doctors who don't want to be involved with assisted dying and with practical issues such as family opposition to a patient's request or where a hospital does not have a MAID policy, he said.

"It is our intention to assist physicians by identifying your potential medical-legal risks based upon the individual scenario facing you at the time," Crosby said. - Steve Mertl, Vancouver, BC

CMAJ 2016. DOI:10.1503/cmaj.109-5324 